\title{
CASE REPORT: ENDOSCOPIC ULTRASONOGRAPHY CAN BE USED AS AN ADJUNCTIVE PROCEDURE IN ATYPICALLY PARATHYROID ADENOMA
}

\section{Neslihan CUHACI ${ }^{1}$, Cevdet AYDIN¹, Osman ERSOY², Aylın KILIC YAZGAN³, Ibrahim KILINC ${ }^{4}$, Reyhan ERSOY'1, Bekir CAKIR}

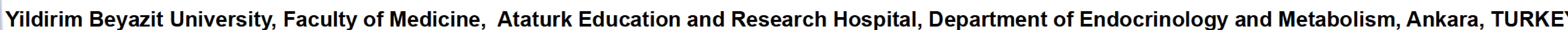
2 Yildirim Beyazit University, Faculty of Medicine, Ataturk Education and Research Hospital, Department of Gastroenterology, Ankara, TURKEY

${ }^{3}$ Ataturk Education and Research Hospital, Department of Pathology, Ankara, TURKEY

${ }^{4}$ Ataturk Education and Research Hospital, Department of General Surgery, Ankara, TURKEY

\section{INTRODUCTION}

$>$ Ectopic and atypically localized parathyroid adenomas such as in the anterior mediastinum, paraesophageal or retrotracheal position, although rare, can be seen in clinical practice.

$>$ Ultrasound (US) which is a frequently used and one of the best conventional imaging modality sometimes fails to identify the lesion especially in atypically localized adenomas.

$>$ Endoscopic US (EUS) is a new technique that can be used for localization of parathyroid lesions.

$>$ We reported a case with paraeosophageal parathyroid adenoma which was localized accurately with EUS.

\section{CASE}

A A 55-years old woman with papillary thyroid microcarcinoma (PTMC) $(0.8 \mathrm{~cm}$ in size) was operated 5 years ago.

$>$ After the thyroid surgery her Ca levels $(10.5-11 \mathrm{mg} / \mathrm{dl})$ were found as elevated.

$>$ She had been evaluated for hypercalcemia and PTH level was also found elevated. In her neck ultrasound (US) and parathyroid scintigraphy no pathology was found.

> Since she had no operation indication for asymptomatic hyperparathyroidism she had been followed for 5 years

> Bone mineral densitometry revealed osteoporosis in lumbal vertebraes. Neck US found no pathology. Recent parathyroid scintigraphy revealed parathyroid adenoma in the posterior of the trachea in the inferior thyroid region.
Neck and upper mediastinal computerised tomography showed heterogenous solid nodular lesion in the superior right paraeosophageal region $11 \mathrm{~mm}$ in size.

$>$ In order to determine the exact localization of the parathyroid adenoma EUS was performed and detected a hypoechoic lesion close to esophagus on the right parathyroid localization

$>$ The patient underwent parathyroidectomy with minimally invasive procedure, parathyroid adenoma was detected and excised

\section{CONCLUSION}

Preoperative localization of parathyroid pathology is important in appropriate cases of minimal invasive surgery.

$>$ EUS can be accepted as a tool for detection of parathyroid adenoma. When the other imaging methods are negative or conflicting, EUS can be considered in these patients 